\title{
Technical note: An improved tool to insert lines for abomasal infusion in rumen cannulated cattle
}

\author{
Edwin Westreicher-Kristen ${ }^{1}$ and Andreas Susenbeth \\ Institute of Animal Nutrition and Physiology, Christian-Albrechts-Universität zu Kiel, 24118 Kiel, Germany
}

\begin{abstract}
An improved tool was tested that facilitates the insertion of abomasal infusion lines in ruminally cannulated cattle for postruminal infusion studies. The insertion device was made from a $68 \times 25 \mathrm{~mm}$ section of 20 - $\mathrm{mm}$ i.d. stainless steel device with a weight of $125 \mathrm{~g}$. The general procedure to place the tool is to pass the insertion device with the infusion line through the rumen cannula, through the sulcus omasi (reticulo-omasal orifice), and finally into the abomasum. Once inside the omasum, the insertion device is placed inside the abomasum by gently shifting the infusion line from the flexible polyvinyl chloride tubing fitted to the insertion device. The insertion device places itself by self-moving down through the abomasal orifice into the abomasum by means of its own weight. After device placement, its position can be verified by palpating through the wall of the rumen. This way, an infusion line can easily be inserted into the abomasum by any person without introducing the hand into the omasum, avoiding possible injuries to the animal and tool being expulsed of its desired position.
\end{abstract}

Key words: rumen, omasum, abomasum, postruminal infusion

\section{Technical Note}

Dietary ingredients are first exposed to microbial fermentation in ruminants, challenging the elaborate procedures to study the fate of nutrients provided for postruminal digestion. Therefore, several approaches were developed to study the fate and the effect of nutrients or substances that escape from rumen fermentation and pass into the abomasum and intestine. Precise quantification of the flow of nutrients or substances to the abomasum or intestine is crucial to determine their digestibility or bioavailability. Therefore, postruminal infusion studies are of great relevance for nutrition

Received October 13, 2016.

Accepted November 30, 2016.

${ }^{1}$ Corresponding author: westreicher@aninut.uni-kiel.de and feed evaluation in cattle. The duodenal cannula remains a valuable component for research on cattle nutrition and has been used for digesta sampling and infusion. However, intestinal surgical procedures are difficult and costly, and cannulas require extensive maintenance and have been frequently criticized due to animal welfare. An alternative procedure allowing abomasal infusion is based on the insertion of an infusion line through the sulcus omasi (reticulo-omasal orifice) into the abomasum; such a technique was reported in cattle for abomasal infusion studies (Derrig et al., 1974; Spires et al., 1975). Moreover, studies of abomasal infusion of fatty acids (Romo et al., 1996; Benson et al., 2001), starch (Knowlton et al., 1998), glucose, and fat (Oldick et al., 1997) have been reported. Recently, Gressley et al. (2006) described a tool that can be used to facilitate the placement of abomasal infusion lines, which was successfully used in several studies (Gressley and Armentano, 2007; Pires et al., 2008; Brickner et al., 2009; Côrtes et al., 2011; Lima et al., 2014). This technique (abomasal infusion) has the advantage of using of rumen cannulas, avoiding the fitting of duodenal cannulas.

Gressley et al. (2006) used a tool to place infusion lines into the abomasum that consisted of 2 pieces, a delivery and an insertion device. According to Gressley et al. (2006), the delivery device was a $23-\mathrm{cm}$ long section of 2.5-cm i.d. polyvinyl chloride (PVC) pipe and the insertion device consisted of a $23-\mathrm{cm}$ long section of $3.8-\mathrm{cm}$ i.d. PVC pipe. The insertion and delivery devices were used to introduce and to place the infusion line into the abomasum, respectively. Handling of delivery and insertion devices for placement of infusion lines are described in detail by Gressley et al. (2006). Although those authors reported that the technique was highly successful, the tool has some disadvantages: (1) a person with a short arm would have difficulty performing this technique; (2) in large cows, it can be difficult to place the infusion line by hand or ensure that it has been definitively placed in the abomasum; (3) the delivery and insertion device length $(23 \mathrm{~cm})$ creates a problem when manipulating it within the reticulum to try to get through the reticulo-omasal ori- 
fice; (4) repeated retraction of the insertion tool from the abomasum and excessive manipulation of the tool in the omasum and abomasum are sometimes required during the placement of the infusion line; (5) the 2 previous aspects may lead to injury of the animal; and, therefore, (6) use of the technique may result in a long and complicated procedure to place the infusion lines. Consequently, the disadvantages may restrict the application and dissemination of the technique. Therefore, in the current study a tool was developed that considerably facilitates the insertion of abomasal infusion lines in ruminally cannulated cattle for postruminal infusion studies.

The complete infusion line described here is pictured in Figure 1. The first part of the infusion line until the rumen cannula is composed of a spiral plastic tube (Figure 1, A), which facilitates the animal to move, lie down, and step without damaging the infusion line or interrupting the nutrient flow during infusion. The second part, beginning at the inner side of the rumen cannulas (\#2C, $10 \mathrm{~cm}$ i.d.; Bar Diamond Inc., Parma, ID) stopper (Figure 1, B), consists of a flexible PVC tubing (Figure 1, C; $2.5 \mathrm{~m}$ long $\times 8 \mathrm{~mm}$ i.d., $2 \mathrm{~mm}$ wall thickness) fitted to the insertion device at the end of the infusion line. To avoid the insertion device being dislodged from the tubing during removal from the abomasum, the tubing was fastened to the connection end of the insertion device with a clamp. To infuse the solutions into abomasum, a thin Tygon tubing (2.06 mm i.d.; Hirschmann, Eberstadt, Germany) was passed through the whole infusion line to the insertion device. To pass the Tygon tubing through the rumen cannula, a hole was drilled in the middle of the cannula stopper to fix an adapter made of stainless steel, which connected the spiral plastic tube with the flexible PVC tubing.

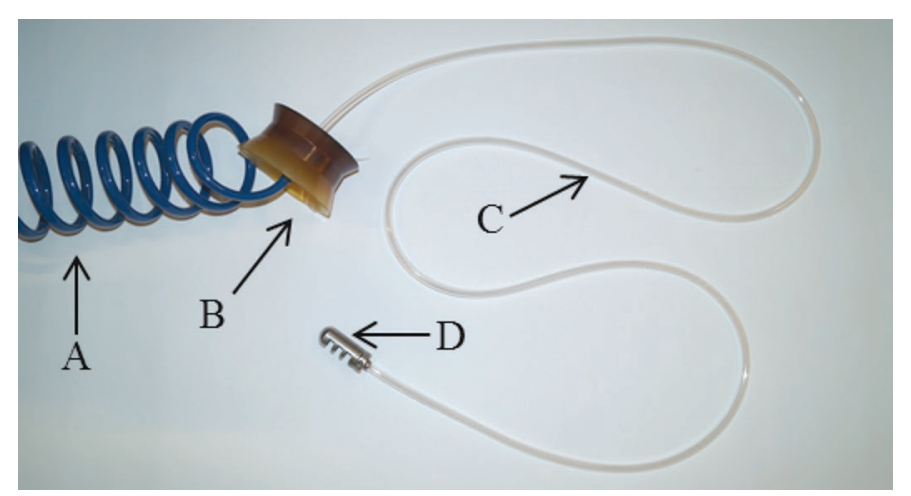

Figure 1. The complete abomasal infusion line with the spiral plastic tube (A), cannula stopper (B), flexible polyvinyl chloride tube line $(\mathrm{C})$, and the stainless steel insertion device (D) at the end of the infusion line. Color version available online.
The insertion device (Figure 2) was made from a 68 $\times 25 \mathrm{~mm}$ section of 20 -mm i.d. round austenitic stainless steel (short name X8CrNiS18-9, material number 1.4305; Deutsche Edelstahlwerke GmbH, Witten, Germany). The insertion device was designed to have a critical weight $(125 \mathrm{~g})$ high enough to permit self-moving of the device down into the abomasum and to anchor the infusion line in the abomasum, and large enough to be easily recognized in the abomasum by palpating through the wall of the rumen. Similar to the procedure of Gressley et al. (2006), the insertion device with the infusion line was passed through the rumen cannula, then through the sulcus omasi, and finally through the omaso-abomasal orifice into the abomasum. In contrast to Gressley et al. (2006), we found using the left arm to be more comfortable to accomplish the procedure. In such a manner, manipulating the insertion device, locating the sulcus omasi, and introducing the device into the omasum were easily and quickly performed.

Once inside the omasum, the insertion device was placed inside the abomasum by gently shifting the infusion line in the direction of the omasum from the flexible

\section{(A)}

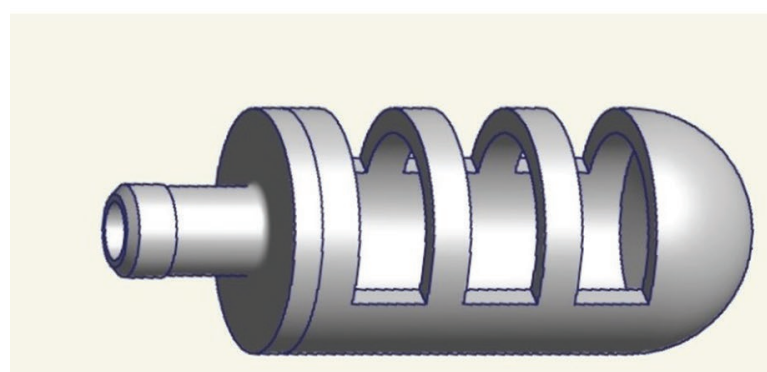

(B)

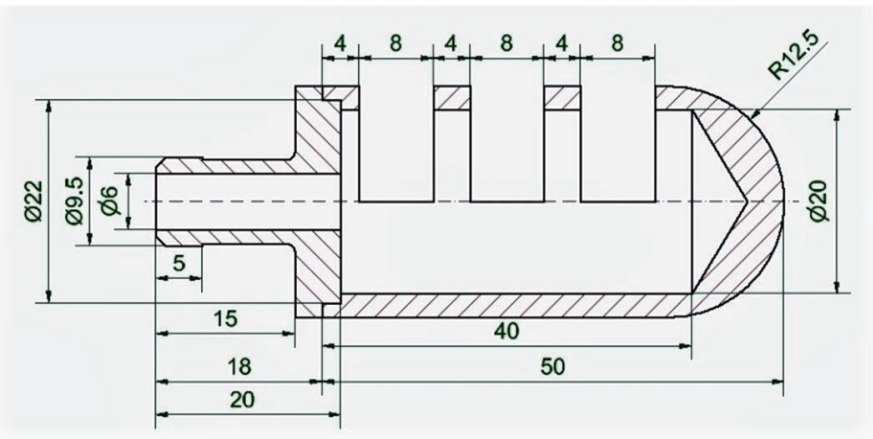

Figure 2. The insertion device made of stainless steel and used at the end of the infusion line displayed in tridimensional form (A), and with dimensions in millimeters (B). Color version available online. 
PVC tubing (Figure 1, C) fitted to the insertion device; therefore, introducing the hand into the omasum and the abomasum was never required. When shifting the insertion device into the abomasum, resistance was rarely felt and, when it happened, the tubing was shifted back slightly a few centimeters; thereafter, shifting forward was continued. Shifting around $50 \mathrm{~cm}$ of the tubing was necessary for the insertion device to reach its desired position in the abomasum. As expected, retraction of the insertion device was not required when introducing it into the abomasum and the insertion device placed itself by self-moving down through the omaso-abomasal orifice into the abomasum by means of its own weight. After device placement into the abomasum, its position could easily be verified by palpating through the wall of the rumen. Additionally, this palpation could be used to pull the infusion line or manipulate the insertion device to a different part of the abomasum. However, we recommend avoiding such handling to minimize possible injuries of the abomasum.

To prove precision and feasibility of the technique, the tool for placing infusion lines into the abomasum was tested during 2015 and 2016 in 2 experiments where starch solutions were infused into the abomasum in cattle (data not presented). In both experiments, 4 heifers $(2$ German Black Pied and 2 Jersey $\times$ German Black Pied) fitted with permanent ruminal cannulas and averaging $565 \pm 29 \mathrm{~kg}$ of $\mathrm{BW}$ were used. Animals were housed in a tiestall with rubber mats. Both studies were performed in accordance with the animal welfare legislation and under approval from the Animal Welfare Commission of the Ministry of Energy, Agriculture, Environment and Rural Areas of the federal state of Schleswig-Holstein, Germany [V 244-7224.121-25 $(100-8 / 14)]$. The heifers were fitted with the infusion lines and the insertion device during 2 trials with 2 periods of $14 \mathrm{~d}$ and 2 periods of $28 \mathrm{~d}$. The position of the infusion line was verified twice a day (before feeding) by palpating the flexible PVC tubing in the reticuloomasal orifice. Simultaneously, position of the insertion device in the abomasum was monitored by palpating through the wall of the rumen, which is recommended after contraction and during the relaxed phase of the rumen. Moreover, long tubing $(2.5 \mathrm{~m})$ between the cannula stopper and insertion device was used to avoid the insertion device being dislodged from the abomasum due to pressure of the rumen contractions or movement of the rumen content. During both experiments, the infusion lines and insertion device remained in the abomasum for the entire infusion periods for $24 \mathrm{~h} / \mathrm{d}$, were never dislodged, and the insertion device was always found in the expected position (ventral part). At the end of the experiments, the stainless steel insertion device was removed by gently pulling the tubing at the reticulo-omasal orifice. We observed neither reduced feed intake nor a change in heifer behavior as a result of the presence of the device in the abomasum. The latter may be explained due to the fact that the tubing passing the sulcus omasi was only $1.0 \mathrm{~cm}$ o.d. and, therefore, obviously did not impair the flow of digesta to the abomasum. Huhtanen et al. (1997) observed a reduction in feed intake of cows using an omasal sampling device fitted to a thicker PVC tube $(1.6 \mathrm{~cm}$ o.d.) during an uninterrupted 21-d period; however, those authors suggested that this was more related to the sampling procedure than the mere presence of the device in the reticulo-omasal orifice.

In conclusion, this improved tool for placing abomasal infusion lines allows placement of the device via a ruminal cannula without introducing the hand through the omasum and into the abomasum, reducing possible injuries to the animal, and enabling any person to place the device easily without it being expelled from its desired position. In general, this improved tool simplifies the procedure of placing infusion lines into the abomasum. Using the proposed tool may reduce the necessity of duodenal cannulated animals to study postruminal digestion in cattle. However, it must be pointed out that this tool facilitates abomasal infusion studies only and is not applicable for quantifying ruminal outflow.

\section{ACKNOWLEDGMENTS}

Authors thank Berndt Neumann from the Faculty of Engineering of Christian-Albrechts-Universität zu Kiel for producing Figure 2 and for manufacturing the insertion device made of stainless steel.

\section{REFERENCES}

Benson, J. A., C. K. Reynolds, D. J. Humphries, S. M. Rutter, and D. E. Beever. 2001. Effects of abomasal infusion of long-chain fatty acids on intake, feeding behavior, and milk production in dairy cows. J. Dairy Sci. 84:1182-1191.

Brickner, A. E., J. A. A. Pires, T. F. Gressley, and R. R. Grummer. 2009. Effects of abomasal lipid infusion on liver triglyceride accumulation and adipose lipolysis during fatty liver induction in dairy cows. J. Dairy Sci. 92:4954-4961.

Côrtes, C., R. Kazama, D. Da Silva-Kazama, C. Benchaar, L. M. Zeoula, G. D. T. Santos, and H. V. Petit. 2011. Digestion, milk production and milk fatty acid profile of dairy cows fed flax hulls and infused with flax oil in the abomasum. J. Dairy Res. 78:293-300.

Derrig, R. G., J. H. Clark, and C. L. Davis. 1974. Effect of abomasal infusion of sodium caseinate on milk yield, nitrogen utilization and amino acid nutrition of the dairy cow. J. Nutr. 104:151-159.

Gressley, T. F., and L. E. Armentano. 2007. Effects of low rumen-degradable protein or abomasal fructan infusion on diet digestibility and urinary nitrogen excretion in lactating dairy cows. J. Dairy Sci. 90:1340-1353.

Gressley, T. F., S. M. Reynal, J. J. Olmos Colmenero, G. A. Broderick, and L. E. Armentano. 2006. Technical note: development of 
a tool to insert abomasal infusion lines into dairy cows. J. Dairy Sci. 89:3965-3967.

Huhtanen, P., P. G. Brotz, and L. D. Satter. 1997. Omasal sampling technique for assessing fermentative digestion in the forestomach of dairy cows. J. Anim. Sci. 75:1380-1392.

Knowlton, K. F., T. E. Dawson, B. P. Glenn, G. B. Huntington, and R. A. Erdman. 1998. Glucose metabolism and milk yield of cows infused abomasally or ruminally with starch. J. Dairy Sci 81:3248-3258.

Lima, L. S., G. T. Santos, A. B. Shogor, J. C. Damasceno, F. E. Marichi, N. W. Santos, F. S. Santos, and H. V. Petit. 2014. Effect of abomasal or ruminal supplementation of citrus pulp and soybean oil on nutrient digestibility and ruminal fermentation of dairy cows. Anim. Feed Sci. Technol. 189:123-129.

Oldick, B. S., C. R. Staples, W. W. Thatcher, and P. Gyawu. 1997. Abomasal infusion of glucose and fat - Effect on digestion, pro- duction, and ovarian and uterine functions of cows. J. Dairy Sci 80:1315-1328.

Pires, J. A. A., B. Pescara, A. E. Brickner, N. Silva del Rio, A. P. Cunha, and R. R. Grummer. 2008. Effects of abomasal infusion of linseed oil on responses to glucose and insulin in Holstein cows. J. Dairy Sci. 91:1378-1390.

Romo, G. A., D. P. Casper, R. A. Erdman, and B. B. Teter. 1996 Abomasal infusion of cis or trans fatty acid isomers and energy metabolism of lactating dairy cows. J. Dairy Sci. 79:2005-2015.

Spires, H. R., J. H. Clark, R. G. Derrig, and C. L. Davis. 1975. Milk production and nitrogen utilization in response to postruminal infusion of sodium caseinate in lactating cows. J. Nutr. 105:11111121. 